\title{
A NOMENCLATURA DOS USOS DA ÁGUA NO BRASIL E A INTERAÇÃO COM A PERCEPÇÃO DA POPULAÇÃO CONSUMIDORA FRENTE AOS CONCEITOS DE ÁGUA VIRTUAL E PEGADA HÍDRICA
}

\author{
Nilza Aparecida Freres STIPP1 \\ Marcia Regina Lopez ARANTES²
}

\section{Resumo}

Os conceitos água virtual e pegada hídrica surgem como grandes contribuições para a ampliação da discussão referente à gestão dos recursos hídricos no planeta. Com o objetivo de garantir a sustentabilidade a longo prazo, torna-se necessária uma mudança profunda nos padrões de consumo que passa obrigatoriamente pela percepção dos usuários, uma vez que a contabilização do volume de água utilizado na produção de bens e serviços ainda é pouco utilizada. Analisando a divisão dos usos da água no Brasil, é possível constatar que o consumo humano é apontado como responsável por $10 \%$ da demanda direta dos recursos hídricos, sendo que efetivamente, considerando o consumo direto e indireto, seria responsável por praticamente $100 \%$ da vazão consumida total. Assim, este estudo avalia a nomenclatura dos usos da água através das vazões de água retirada, consumida e de retorno e apresenta uma nova proposta de nomenclatura de usos da água, considerando o consumo direto através do abastecimento humano e animal, tanto no meio urbano quanto rural e o consumo indireto representado pela irrigação para produção de alimentos e a industrialização de produtos, ao mesmo tempo em que discute a importância desta mudança no processo de sensibilização ambiental do usuário. dora.

Palavas-chave: Água virtual. Pegada hídrica. Usos da água. População consumi-

\section{Abstract \\ The nomenclature of uses of water in Brazil and the interaction with the perception of the consumer population in face of the concepts of virtual water and water footprint}

The concepts of virtual water and water footprint arise as big contributors to the extension of the debate related to the planet's water resource management. With the purpose of obtaining long term sustainability, it becomes necessary a deep change regarding the consumption patterns that passes mandatorily through the perception of the users, since the accounting of the water volume used in the production of goods and services is still not utilized enough. Analyzing the division of water use in Brazil, it is possible to verify that the human consumption is pointed out as responsible for $10 \%$ of the direct demand of water resource, even though effectively, considering the direct and indirect consumption, it would be responsible for basically $100 \%$ of the total water flow consumption. Therefore, this paper evaluates the nomenclature of water use through water flow withdrawal, water consumption, and return flow, and presents a new nomenclature proposal of water use, considering the direct consumption through human and animal supply, both in the urban and in the rural environment and the indirect consumption represented by the irrigation for food production and product industrialization, as well as discusses the importance of this change in the process of the user's environmental awareness.

Key words: Virtual water. Water footprint. Uses of water. Consumer population.

\footnotetext{
${ }^{1}$ UEL. Profa. Dra. do Programa de Pós-Graduação em Geografia. Rua Tijuca, 182 - Parque do Lago Juliana - CEP 86.015-230 - Londrina/PR. E-mail: nfreres@sercomtel.com.br

2 UEL. Doutoranda do Programa de Pós-Graduação em Geografia. Rua Orlando Maimone, 260 - apt. 304 - bl. H. CEP 86.046.530 - Londrina/PR. E-mail: marcia.arantes3@yahoo.com.br
} 


\section{INTRODUÇÃO}

Conforme demonstrado por Rebouças (2002, p. 7-8) o total de água disponível no planeta está na ordem de 1.386 milhões de $\mathrm{Km}^{2}$, sendo $97,5 \%$ de água salgada e $2,5 \%$ de água doce. Este volume de água doce apresenta um percentual de $68,9 \%$ disposto em calotas polares e geleiras, 29,9\% em água subterrânea, 0,3\% em rios e lagos e 0,9\% em outros reservatórios, como por exemplo, o vapor na atmosfera e a biomassa. Considerando a dificuldade atual de acesso aos recursos hídricos disponíveis nas calotas polares e geleiras, o volume de água disponível para os diversos tipos de uso pela população, torna-se limitado.

A escassez hídrica desponta como um problema emergencial global, uma vez que o Relatório intitulado Revisão da Projeção Mundial 2015, elaborado pelo Departamento de Assuntos Econômicos e Sociais da ONU e divulgado em julho de 2015, apresenta uma projeção para a população mundial que iria dos 7.3 bilhões em 2015 para 8,5 bilhões em 2030, 9,7 bilhões em 2050 e mais de 11 bilhões de pessoas em 2100 (ONU, 2015, p. 01). Para o Brasil, os dados apontam um crescimento populacional onde dos 207.848 estimados em 2015 chegará aos aproximados 238.270 habitantes em 2050, com redução para 200.305 em 2100 (ONU, 2015, p. 28).

Além dos dados de crescimento populacional e escassez, ainda existem outras implicações que dificultam o acesso à água doce, como a distância das fontes em relação aos consumidores, o desperdício e especialmente a contaminação, sendo necessário um gerenciamento diferenciado e inovador dos recursos hídricos disponíveis.

Um novo gerenciamento está vinculado à percepção da população, uma vez que o consumo da água para a grande maioria das pessoas está atrelado à sua fatura mensal, ou seja, à água consumida diretamente (higiene pessoal, limpeza, alimentação) e não faz relação com a água embutida em produtos usados ou consumidos diariamente (utensílios, alimentos, roupas, calçados) ou estilo de vida (transporte, lazer, etc).

Esta percepção encontra-se apoiada, em grande parte, na divisão dos usos da água. No Brasil, atualmente, a agricultura consome, em média, $70 \%$ do total de água doce, divididos os $30 \%$ restantes entre consumo industrial, comercial e doméstico. Assim, a população consumidora final não teria, em tese, vínculo com a água utilizada na agricultura, na indústria e no comércio.

Os paradigmas e a forma como o recurso água é percebido e tratado, tanto no meio público como no privado, especialmente a grande população consumidora, precisam, portanto, ser revistos.

\section{OBJETIVOS}

Propor uma nova nomenclatura para os usos da água no Brasil através da utilização dos conceitos de água virtual e pegada hídrica, como forma de auxiliar na percepção da população consumidora.

\section{METODOLOGIA}

Neste trabalho adotou-se o método empírico, que se baseia na coleção de uma grande quantidade de dados de um fenômeno natural e a partir da análise dos dados fundamentar uma teoria ou chegar a uma determinada conclusão. Os dados empíricos 
podem ser coletados por meio da observação sistemática de um fenômeno ou através de um experimento controlado.

$\mathrm{Na}$ ciência, o empirismo é normalmente utilizado quando se fala no método científico tradicional (que é originário do empirismo filosófico), o qual defende que as teorias científicas devem ser baseadas na observação do mundo, em vez da intuição ou da fé, como teria sido no passado. Não obstante estar este termo ligado ao senso comum, a ciência e a filosofia se apropriaram dele emprestando-lhe rigor e atribuindo-Ihe valor. E assim o conhecimento empírico foi incorporado ao método científico e foi transformado em escola filosófica.

Um conceito central na ciência moderna é que toda evidência deve ser empírica, ou seja, baseada em dados reais observados na natureza.

Por meio de um ensaio teórico sobre a temática abordada procurou-se evidenciar aqui a importância dos conceitos de Água Virtual e Pegada Hídrica vinculados à nomenclatura dos usos da água, no desenvolvimento e reconhecimento dos padrões utilizados atualmente, através de uma pesquisa histórico-bibliográfica que demonstra como esses conceitos se mostram conectados, uma vez que detêm objetivos comuns.

\section{DESENVOLVIMENTO}

\section{ÁGUA VIRTUAL E PEGADA HÍDRICA}

O conceito "água virtual" foi apresentado por John Anthony Allan, professor de Geografia, no ano de 1993, em um Seminário na Universidade de Londres. Anteriormente, o autor havia utilizado o termo "água embutida" com base em ideias de economistas israelenses sobre a exportação de água através de produtos como laranja e abacate do semiárido daquele país (MERRETT, 2003, p. 4-5).

Do Carmo et al. (2007) colocam que a idéia principal deste conceito está ligada à agricultura, uma vez que trata de commodities da água incorporada nos produtos que circulam entre países, alterando as políticas que envolvem o comércio mundial e ainda que "a função maior desse mecanismo então seria a de possibilitar às diferentes localidades uma produção de maneira a não onerar seus recursos e, ao mesmo tempo, possibilitar o comércio entre os que têm abundância ou escassez de recursos hídricos".

O conceito também abre discussões atuais e importantes como a cobrança pelo uso da água e o modo como países com déficit hídrico recebem produtos, principalmente primários, de países com abundância hídrica - e como regiões com abundância hídrica como a Amazônia, no Brasil, poderiam se tornar grandes exportadoras de produtos (DO CARMO et al., 2007).

A adoção de ferramentas que ampliem a discussão sobre a gestão da água entre os diferentes usuários é um dos objetivos para a sustentabilidade. Nesta perspectiva, além da água virtual, surge o conceito da "pegada hídrica", que "vem sendo utilizado como um indicador de caráter multidimensional do consumo de água, sendo apropriado por diferentes setores da sociedade na contabilização do volume de água usado para produzir bens e serviços" (LEÃO, 2013, p. 159).

O conceito foi introduzido em 2002 por Hoekstra como um "indicador multidimensional, que mostra os volumes de consumo de água por fonte e os volumes de poluição pelo tipo de poluição; todos os componentes de uma pegada hídrica total são especificados geográfica e temporalmente" (HOEKSTRA et al., 2011, p. 2). 
A pegada hídrica pertence à família das pegadas, composta também pelas Pegadas Ecológica e de Carbono. As pegadas são indicadores que "permitem uma representação de múltiplos aspectos das consequências e impactos das atividades humanas ao capital natural" e inclui a avaliação do consumo de uma pessoa, de uma determinada parcela da população, de um território, de um país, de um estado ou de uma cidade, considerando os três compartimentos chave dos ecossistemas: biosfera, atmosfera e hidrosfera, para garantir e/ou sustentar determinado estilo de vida (BECKER, et al., 2012, p. 32).

Os indicadores de sustentabilidade atualmente utilizados, dos quais a pegada hídrica emerge, surgiram a partir de vários estudos e relatórios com apontamentos preocupantes quanto ao modelo de desenvolvimento mundial estabelecido, como o Relatório intitulado Limites ao Crescimento, publicado por Meadows, em 1972, o Relatório Brundtland (Nosso Futuro Comum) do PNUD, publicado em 1983 e mais uma vez reforçado em 1992 por ocasião da publicação do Apelo dos Cientistas do Mundo à Comunidade na Conferência das Nações Unidas sobre Meio Ambiente e Desenvolvimento - Rio 92. Estes relatórios trazem em comum não só o alerta quanto à degradação da condição humana a longo prazo, mas também quanto à necessidade da criação de novos indicadores de desenvolvimento sustentável, como contribuição à tomada de decisões. (BECKER, et al., 2012, p. 20).

Fernandez e Mendiondo (2011, p. 05-06) atentam para a importância da incorporação dos aspectos econômicos e políticos na avaliação dos recursos hídricos e da ligação entre problemas climáticos, escassez, políticas públicas e a necessidade de adaptação a mudanças de longo prazo, uma vez que a escassez hídrica é um viés negativo das mudanças climáticas. Ainda, de acordo com Da Silva et al. (2013, p. 104)

A pegada hídrica e a pegada ecológica sugerem a possibilidade de que a demanda por recursos naturais pela humanidade é maior do que o planeta pode fornecer de forma sustentável. Esse excesso de consumo é definido de forma significativa devido à rápida expansão econômica, bem como a urbanização, migração, mudanças de estilo de vida e outras grandes transições sociais.

A pegada hídrica é um método de avaliação que se difere por separar e classificar a água doce de acordo com sua fonte e impacto, definida como Blue Water ou Água Azul, que é a água consumida diretamente e oriunda dos corpos hídricos superficiais ou subterrâneos; Green Water ou Água Verde, definida como a quantidade de precipitação que fica armazenada no solo, ou seja, não sofre escoamento superficial e não abastece os lençóis freáticos, tendo como principal fim o consumo pelas plantas; Grey Water ou Água Cinza, que é a quantidade de água necessária para diluir ou assimilar a carga de poluentes gerada em processos antrópicos (BECKER, et al., 2012, p. 2).

Apesar de trazer uma contribuição muito importante, a partir do momento em que traz à luz o conceito da água consumida e não contabilizada pelas pessoas, Empinotti e Warner (2012, p. 157-164) acrescentam que o conceito apresenta falhas quando aponta que países com maior disponibilidade hídrica teriam uma certa vantagem econômica sobre países com déficit hídrico nas práticas de importação e exportação de alimentos.

O fator estratégico e político nas relações comerciais, pode ser comprometido caso não sejam considerados e avaliados os valores ecológicos, culturais, sociais e políticos da água, especialmente práticas agrícolas tradicionais que espacializam-se além da perspectiva econômica - principal conceito da água virtual - uma vez que afetariam diretamente e negativamente o estilo de vida de determinadas populações 
rurais, podendo priorizar a produção de culturas exportadoras em detrimento da agricultura de subsistência ou de produtos com valor cultural.

Neste contexto, estudos apontam que a apropriação da terra em regiões com maior abundância de água, tem sido uma das estratégias para garantir a segurança hídrica e alimentar de países em condição de déficit hídrico. Empresas transnacionais também têm utilizado essa estratégia no cultivo de biocombustíveis e alimentos, demonstrando que no contexto geopolítico global, os países importadores de água não estão em desvantagem ou dependência, como pressupõe o conceito da água virtual.

Empinotti e Warner (2012, p. 163) expõem esta perspectiva ao abordar que

os países produtores em territórios estrangeiros estão protegendo os seus recursos hídricos e os aplicando em diferentes atividades, ao mesmo tempo externalizando e exportando seus problemas de escassez de água para países com fragilidade não só hídrica mas também alimentar. Com isso, os países produtores de alimentos assumiram os custos ambientais e sociais da produção de commodities que serão consumidos por outros e não por sua população. Assim, o acesso à água e à terra se mantêm como recursos estratégicos, mas a sua localização não garante posições de controle a estes Estados como sugerido pela aplicação da água virtual e da pegada hídrica nas práticas de produção e comercialização de produtos agrícolas.

Esta análise é compartilhada por Fernandez e Mendiondo (2011, p. 5), que defendem que a dimensão econômica do conceito de água virtual fica evidenciada, bem como o risco da manutenção dos ecossistemas de países exportadores de água virtual, especialmente através do uso inadequado do recurso, aplicação de agrotóxicos, fertilizantes e outros, comuns à agricultura tradicional.

Diante deste cenário, a atuação do poder público e a sensibilização ambiental da população consumidora tornam-se essenciais no processo de mudança, e ferramentas como a pegada hídrica e a água virtual são indicadores ambientais que podem dimensionar o consumo, a ocupação do solo, a geração de resíduos sólidos, além de outros fatores, conforme evidenciado por Fernandez e Mendiondo (2011, p. 6)

Diante de um cenário com crescente demanda de água e consumo de produtos, bens e serviços, verifica-se a necessidade de medidas não-estruturais, incluindo políticas públicas relacionadas à educação para um consumo mais sustentável e medidas que permitam, por exemplo, que o consumidor escolha o produto que requer menor quantidade de água na sua produção ou cadeia produtiva.

Analisando-se os fundamentos abordados nestes conceitos e de acordo com Fernandez e Mendiondo (2011, p. 11), que apontam que a análise e o conhecimento da pegada hídrica residencial é um importante fator de educação ambiental, uma vez que é possível trabalhar a educação e sensibilização ambiental em cenários futuros de estresse hídrico, decorrente de mudanças climáticas e a atuação das políticas públicas necessárias e ainda esclarecem que "a partir do consumo de águas reais e virtuais, cada grupo de moradores poderão conhecer melhor qual o seu impacto sobre o meio ambiente decorrente do seu uso da água", propõe-se a mudança na nomenclatura dos usos da água no Brasil. 


\section{OS USOS DA ÁGUA NO BRASIL}

Um dos aspectos iniciais desta abordagem refere-se ao modo como a distribuição do uso da água é analisada/avaliada e principalmente, apresentada para os diversos tipos de consumidores. Para isto, foi efetuada uma pesquisa junto às instituições gestoras de recursos hídricos no Brasil, especialmente o Ministério do Meio Ambiente (MMA) e a Agência Nacional de Águas (ANA).

O Ministério do Meio Ambiente publicou em 2011 uma Revisão do Plano Nacional de Recursos Hídricos (PNRH), originalmente editado em 2006, com as ações prioritárias para o período 2012-2015. Fundamentado na Lei Federal 9.433/97 o PNRH possui três objetivos principais que são assegurar

a) a melhoria das disponibilidades hídricas, superficiais e subterrâneas, em qualidade e quantidade;

b) a redução dos conflitos reais e potenciais de uso da água, bem como dos eventos hidrológicos críticos;

c) a percepção da conservação da água como valor socioambiental relevante (MMA, 2011, p. 9).

Com objetivos claros e abrangentes, o documento aposta no trinômio responsável pela implementação do Plano, definido como: poder público, setor usuário e sociedade civil.

Na revisão do PNRH mantém-se essa divisão por setores usuários, mas avança no sentido de apresentar uma nova dimensão de avaliação, constante nas 22 prioridades elencadas, que é "a preparação das bases para o enfrentamento de desafios futuros, especialmente os resultantes de mudanças climáticas globais e/ou eventos extremos" (MMA, 2011, p. 7).

Esta nova dimensão de análise corrobora com as mais recentes pesquisas relacionadas aos recursos hídricos no planeta, nas quais manter a oferta de água e consequentemente garantir a segurança alimentar da população nos próximos anos é o grande desafio da humanidade, em decorrência do aumento contínuo do consumo, da superexploração das reservas subterrâneas e das alterações climáticas. De acordo com Michel Jarraud, Presidente da ONU-Água e Secretário Geral da Organização Meteorológica Mundial - OMM,

Já existe um consenso internacional de que água e saneamento são essenciais para que muitos dos Objetivos de Desenvolvimento do Milênio sejam atingidos. Eles estão indissoluvelmente ligados a questões como mudança climática, agricultura, segurança alimentar, saúde, energia, equidade, questão de gênero e educação. Agora, devemos olhar para a frente, com vistas à mensurabilidade, ao monitoramento e à implementação" (ONU BR - Nações Unidas do Brasil, 2015).

Considerando estas questões, especialmente em relação à divisão de usos da água, já existe um ponto de apoio para a introdução de novos conceitos de gestão através das análises das vazões de retirada e de consumo para os diferentes usos, publicado pela Agência Nacional de Águas no documento intitulado "Conjuntura dos recursos hídricos no Brasil: informe 2015".

Estas análises têm como base o PNRH - Volume 1, publicado pelo MMA onde define primeiramente os usos consuntivos como "aqueles que implicam a redução da quantidade hídrica" e não consuntivos da água "aqueles que não afetam significativamente a quantidade da água" no país (MMA, 2006, p. 208). 
Exemplos de usos não consuntivos são as atividades de navegação, recreação, hidroeletricidade e piscicultura, dentre outras, que apesar de não afetarem a disponibilidade hídrica, podem ter efeitos diretos sobre a qualidade ou o regime de vazões de um curso d'água (MMA, 2006, p. 208).

Os usos consuntivos e de maior interesse nesta discussão "referem-se principalmente aos usos urbano (doméstico e público), rural (comunidades), agropecuário (irrigação e animal) e industrial" (MMA, 2006, p. 208).

Neste panorama estão definidas as vazões, estabelecidas PNRH (MMA, 2006, p. 208), onde foram consideradas três classes de vazões:

\begin{abstract}
vazão de retirada, que corresponde à vazão extraída pelo usuário; vazão de retorno, que corresponde à parcela de água extraída que retorna ao manancial; e vazão de consumo, que é calculada pela diferença entre as vazões de retirada e de retorno, ou seja, a vazão efetivamente consumida.
\end{abstract}

No documento intitulado "Conjuntura dos recursos hídricos no Brasil: informe 2015" publicado pela ANA (2015, p. 36 ) as figuras 1 e 2 representam, respectivamente, as vazões de retirada total e consumida total, com base em dados federais, especialmente o IBGE.

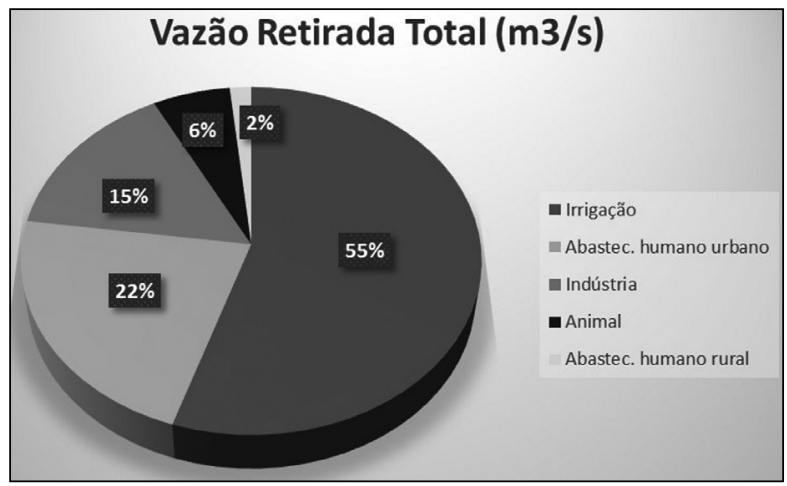

Figura 1 - Vazão de Retirada Total

Fonte: Agência Nacional de Águas, 2015, p. 36.

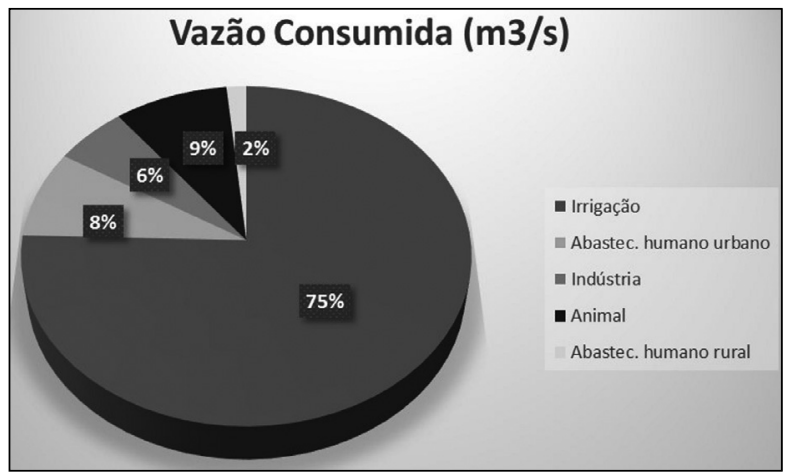

Figura 2 - Vazão Consumida Total

Fonte: Agência Nacional de Águas, 2015, p. 36. 
Do total de retirada dos mananciais de abastecimento do país, o valor apresentado pela ANA é de $2.275,07 \mathrm{~m}^{3} / \mathrm{s}$ e a vazão consumida é de $1.209,64 \mathrm{~m}^{3} / \mathrm{s}$, ou seja, do total de água extraída para os usos consuntivos no país, $53,16 \%$ será efetivamente consumida direta e indiretamente pelos usuários e $46,84 \%$ retornará aos mananciais.

Deste total de água consumida $\left(1.209,64 \mathrm{~m}^{3} / \mathrm{s}\right)$ através dos percentuais apresentados na figura 2, a maior parte tem como destino a agricultura (75\%), seguido pela dessedentação de animais ( $9 \%$ ) abastecimento humano urbano $(8 \%)$, indústria $(6 \%)$ e abastecimento humano rural (2\%). Estabelecendo a relação com a percepção humana sobre consumo de recursos hídricos, esta forma de apresentação dos percentuais é bastante confusa considerando os conceitos de água virtual e pegada hídrica, uma vez que grande parte deste recurso hídrico efetivamente utilizado pela irrigação, animais e indústria, que corresponde a $90 \%$ do valor total, estará presente nos alimentos (cereais, verduras, frutas, legumes, carnes, etc.) e produtos (industrializados, combustível, etc.) que serão consumidos indiretamente pela população.

Assim, temos a população como responsável final pelo consumo direto e indireto de praticamente $100 \%$ dos recursos hídricos relacionados à vazão consumida no país, e não somente $10 \%$ como apresentam os gráficos e análises oficiais correlacionadas.

A partir desta constatação percebe-se que ainda existe um distanciamento entre gestores públicos quanto aos setores de análise hídrica. A sociedade civil, ou seja, a população definida como beneficiária do abastecimento humano urbano e rural, seria responsável somente pelo consumo direto, que representa aproximadamente $10 \%$ do volume total dos recursos hídricos utilizados/consumidos no país. Já o setor usuário, que utiliza a água com fins econômicos, representado na figura 2 como indústria, animal e irrigação é considerado responsável por aproximadamente $90 \%$ da vazão consumida total no montante final dos usos.

Analisando a percepção do usuário direto, ou seja, o consumidor humano, morador do campo ou da cidade, não aparece nenhuma relação do seu uso em $90 \%$ do consumo de água. Desta forma, propagandas e solicitações contínuas de marketing para redução no consumo de água pela população tornam-se inócuas, uma vez que subjetivamente, estes consumidores são responsáveis por $10 \%$ do total da demanda consuntiva dos recursos hídricos no país, sendo por isso aqui proposta uma nova nomenclatura para os usos, utilizando-se os conceitos de água virtual e pegada hídrica, especialmente no que se refere ao consumo indireto dos recursos hídricos.

Quanto à vazão de retorno, estimada pela ANA (2015) em 1.065,63 m³/s $(46,84 \%$ da vazão de retirada total) os resultados apontam que do total de recursos hídricos que retornam aos mananciais, a maior parte (38\%) advém do abastecimento humano urbano. A irrigação ocupa o segundo lugar (32\%), seguida pela indústria (26\%). A vazão de retorno dos usos dos animais e para o abastecimento humano rural ocupam a última posição, com $2 \%$ cada (Figura 3).

Em relação aos percentuais relativos às vazões de retorno cabem análises complementares, uma vez que segundo o PNRH (MMA, 2006, p. 209) esta vazão refere-se à água que foi retirada (vazão de retirada) mas que retornou aos mananciais, e a análise pormenorizada limita-se ao abastecimento humano urbano quando estabelece que "este retorno constitui-se de efluentes sanitários, que requerem tratamento antes de serem lançados nos corpos receptores". 


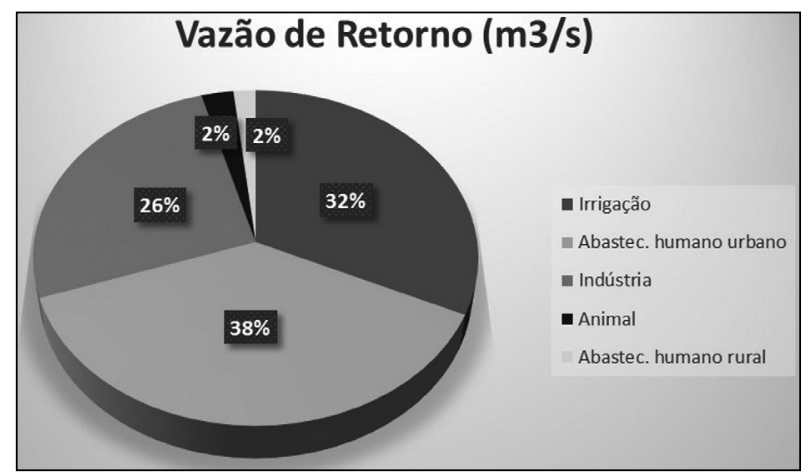

Figura 3 - Vazão de Retorno Total

Fonte: Agência Nacional de Águas, 2015.

Organização: Stipp e Arantes, 2016.

No entanto, os resultados finais apresentados no PNRH apontam os percentuais de vazão de retorno de todas as categorias, sem a análise correspondente. Conforme especificado, a maior parte (38\%) refere-se ao abastecimento humano urbano, onde a água retorna na forma de esgoto sanitário, águas de lavagem e outros. Quanto à irrigação, o documento não especifica as formas de retorno, mas basicamente é a água que evapora e/ou infiltra no solo. Na indústria, o principal retorno é na forma de efluentes industriais. No uso animal, este retorno ocorre na forma de efluentes/esgotos e transpiração, e para o abastecimento humano rural utiliza-se a mesma base de análise do abastecimento humano urbano.

Assim, tem-se que todas as categorias de vazão de retorno apresentam duas características em comum: a água retorna ao manancial após o uso direto e deve passar por tratamento para manter a sua qualidade, à exceção da agricultura, estabelecendo uma correlação direta com os conceitos de água virtual e pegada hídrica, onde essas águas são caracterizadas como "água cinza". Segundo Becker, et al (2012, p. 32) "monitorando os fluxos de água reais e ocultos, a Pegada Hídrica pode ser utilizada para informar sobre os impactos que as atividades humanas causam na hidrosfera".

Além de ser um modelo inovador de avaliação, uma vez que agrega não só o consumo de água por habitante mas traz embutido o conceito de "água virtual", esta proposta estabelece a ligação com a poluição, através da análise da água cinza, e neste caso, pode ser aplicada em todas as categorias de uso. Trata, portanto, da "gestão de recursos hídricos sobre consumo e poluição da água ao longo de toda a cadeia de produção e abastecimento" (HOEKSTRA, 2011, p. 1).

Neste aspecto, através das vazões de retirada total, consumida total e de retorno total, estabeleceu-se a razão percentual entre as três classes de vazões (Figura 4), utilizando-se como base a vazão de retirada total e consumida total apresentada no Relatório de Conjuntura dos Recursos Hídricos no Brasil: Informe 2015 (ANA, 2015): 


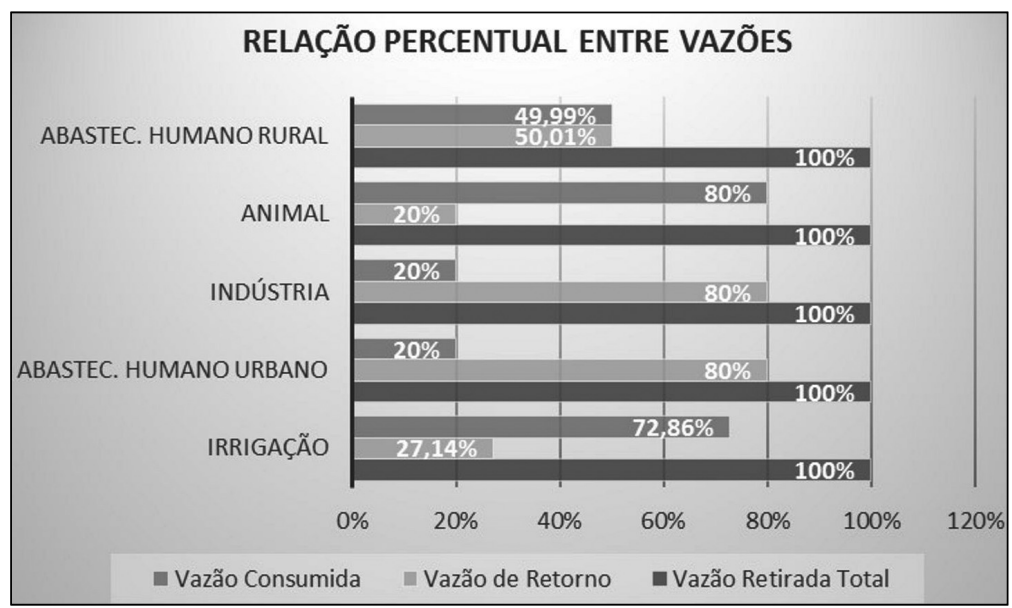

Figura 4 - Relação Percentual entre Vazões

Fonte: Agência Nacional de Águas, 2015. Organização: Stipp e Arantes, 2016.

Em última análise, a relação percentual entre as vazões demonstra que existe uma discrepância nos dados apresentados especialmente quanto às relações de vazão de consumo e de retorno para o abastecimento humano rural e urbano. Considerando-se que a vazão de retorno para abastecimento humano constitui-se de efluentes sanitários e foi utilizada como base a estimativa populacional do IBGE (ANA, 2015, p. 36), as vazões de consumo e de retorno para abastecimento humano urbano e rural, em relação à vazão de retirada total, deveriam equiparar-se nos percentuais, o que não ocorre, independente da existência de sistemas de coleta de esgoto sanitário em áreas urbanas ou fossas nas áreas rurais. Assim, poderão ser fruto de pesquisas mais aprofundadas nos próximos relatórios da ANA.

Quanto à irrigação e à criação/dessedentação de animais, as vazões de consumo são altas, e a água estará sendo utilizada indiretamente pela população, através do consumo final, em razão dos conceitos de água virtual e pegada hídrica.

$\mathrm{Na}$ análise com relação à vazão consumida e de retorno na indústria, foram utilizadas as outorgas estaduais e federais (ANA, 2015, p. 36) e esta também poderá sofrer pesquisas mais aprofundadas, especialmente por tipologia e produtos fabricados.

\section{AVALIAÇÃo DA PEGADA HÍDRICA}

A pegada hídrica é uma medida de consumo e poluição da água e não avalia a severidade do impacto ambiental simplesmente quanto à quantidade de consumo e poluição da água, uma vez que esta depende também da vulnerabilidade do sistema hídrico local e do número de consumidores e poluidores que utilizam o mesmo sistema. Assim, a pegada hídrica apresenta como proposta a "discussão sobre o uso e a alocação equitativos e sustentáveis da água, além de formar uma boa base para a avaliação dos impactos ambientais, sociais e econômicos" (HOEKSTRA, 2011, p. 3). 
A pegada hídrica difere-se da avaliação simples de captação de água, utilizada comumente no meio público e privado, uma vez que inclui as águas verde e cinza no sistema, inclui o uso indireto da água e não inclui a vazão de retorno. Na representação esquemática dos componentes da pegada hídrica proposto por Hoekstra et al. (2011, p. 3) e demonstrado na figura 5, o consumo da água representado pelas pegadas hídricas azul e verde apresenta tanto o uso direto quanto o indireto e exclui do cálculo a água captada que retorna para o local de origem. A poluição é representada pela pegada hídrica cinza e também é calculada a partir do uso direto e indireto da água.

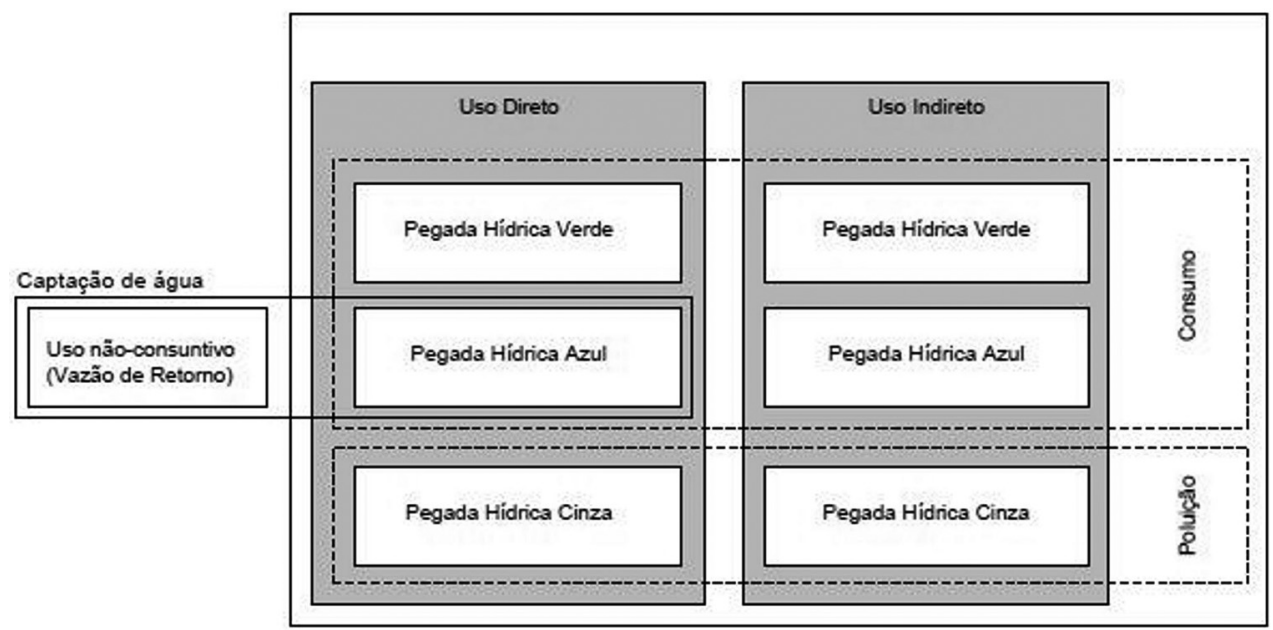

Figura 5 - Representação Esquemática dos Componentes de uma Pegada Hídrica

Fonte: Hoekstra, 2011, p. 03.

Conforme pôde ser visualizado na representação esquemática, apesar de não ser contabilizado na pegada hídrica, o uso não-consuntivo da água captada é apresentado como sinônimo de vazão de retorno. A utilização destes termos como sinônimos confrontam-se com as definições técnicas utilizadas no Brasil nas publicações dos principais órgãos oficiais, uma vez que os usos não consuntivos no país referemse aos usos que não afetariam a disponibilidade hídrica e a vazão de retorno compõese da água extraída que retorna ao manancial após o uso direto, na forma de esgotos e efluentes.

Assim, seria necessário, inicialmente, alinhar estas definições. Considerando o PNRH, nesta análise a vazão de retorno permanece como a água que retorna ao manancial após o uso direto (esgoto doméstico, efluentes industriais, etc).

Conforme exposto acima, com as bases vinculadas ao $\mathrm{PNRH}$, a introdução dos conceitos de água virtual e pegada hídrica no conjunto das análises se dará a partir da mensuração, onde a vazão de consumo será definida como água azul e verde (em $\mathrm{m}^{3} / \mathrm{s}$ ) efetivamente consumida de forma direta ou incorporada aos produtos e serviços, através do consumo indireto. A vazão de retorno está definida como a água cinza.

De acordo com os apontamentos de Fernandez e Mendiondo (2011, p. 9) "em termos gerais da pegada hídrica de um país, consumo doméstico de água, verifica-se 
que a pegada hídrica mundial é da ordem de 4,6\%. O restante corresponde ao consumo de água industrial $(9,6 \%)$ e ao consumo de produção agrícola $(85,8 \%)^{\prime \prime}$ No entanto, a partir da constatação de que este consumo de $4,6 \%$ corresponde somente ao uso direto dos recursos hídricos e de que existe toda uma cadeia produtiva elaborada para a alimentação humana e animal e a industrialização de bens de consumo que fazem parte do consumo indireto de água de cada ser humano, verifica-se que estes usuários finais podem representar uma mudança significativa na redução do uso da água através da análise de seu modo de vida, evitando, por exemplo, o desperdício de alimentos, o transporte oneroso, o consumo de determinados tipos de produtos ou serviços, dentre outros.

\section{PROPOSTA DE NOVA TERMINOLOGIA PARA OS USOS DA ÁGUA NO BRASIL}

Estes novos conceitos da água virtual e de pegada hídrica expõem principalmente o consumo indireto dos recursos hídricos e a nomenclatura proposta a seguir tem como objetivo principal expor a água virtual presente principalmente em produtos e serviços visando uma nova percepção da população consumidora (Tabela 1). Tabela 1 - Proposta de nova terminologia para
os usos da água no Brasil

\begin{tabular}{l|l}
\hline \multicolumn{1}{c|}{$\begin{array}{c}\text { Nomenclatura Atual } \\
\text { Vazão de consumo }\end{array}$} & \multicolumn{1}{c}{$\begin{array}{c}\text { Nomenclatura Proposta } \\
\text { Vazão de consumo }\end{array}$} \\
\cline { 1 - 2 } Irrigação & $\begin{array}{l}\text { Consumo Indireto } \\
\text { Irrigação para produção de alimentos }\end{array}$ \\
\cline { 1 - 2 } Abastecimento humano urbano & $\begin{array}{l}\text { Consumo Direto } \\
\text { Abastecimento humano e animal } \\
\text { (urbano e rural) }\end{array}$ \\
\cline { 1 - 2 } Abastecimento humano rural & $\begin{array}{l}\text { Consumo Indireto } \\
\text { Industrialização de produtos }\end{array}$ \\
\hline Indústria &
\end{tabular}

\section{CONSIDERAÇÕES FINAIS}

Novas pesquisas nesta área podem contribuir para um melhor entendimento dessa temática da atualidade, ainda mais diante da problemática da escassez da água no planeta que vem preocupando a maior parte dos estudiosos sobre os recursos hídricos. Daí a necessidade da construção de novas bases epistemológicas, novos paradigmas para o estudo tanto da água virtual quanto da pegada hídrica, para que se resgate e se reconstruam as bases teóricas e metodológicas que hoje se encontram dispersas entre as várias ciências ambientais. 


\section{REFERÊNCIAS}

ANA - AGÊNCIA NACIONAL DE ÁGUAS. Conjuntura dos recursos hídricos no Brasil: Informe 2015. Brasília: ANA, 2015. 88p.

BECKER, $M$. et al. A pegada ecológica de Campo Grande e a família de pegadas. Brasília: WWF-Brasil, 2012. 132 p. Disponível em <http://www.footprintnetwork.org/ images/article_uploads/pegada_ecologica_campo_grande_2012.pdf>. Acesso em 12 out. 2015.

DA SILVA, et al. Uma medida de sustentabilidade ambiental: Pegada hídrica. Revista Brasileira de Engenharia Agrícola e Ambiental. Campina Grande, PB. v. 17, n.1, p. 100-105, 2013.

DO CARMO, R. L. et al. Água virtual, escassez e gestão: o Brasil como grande exportador de água. Ambiente \& Sociedade. v. X. n. 1. Campinas, Jan/Jun. 2007. Disponível em <http://www.scielo.br/scielo.php?script=sci_arttext\&pid=S1414$753 \times 2007000200006 \&$ Ing $=p t \& n r m=i s o \& t$ Ing $=p t>$. Acesso em $0 \overline{1}$ jun. 2016.

EMPINOTTI, V. ; WARNER, J. Água Virtual e Pegada Hídrica: as contribuições e desafios que estes conceitos trouxeram à maneira como discutimos os recursos hídricos. In: EMPINOTTI, V. ; JACOBI, P. R. (Org.). Pegada Hídrica: inovação, corresponsabilização e os desafios de sua aplicação. São Paulo: Editora Annablume, 2012. 8, p. 155-168.

FERNANDEZ, J. A. B. ; MENDIONDO, E. M. Água Virtual na Gestão de Águas Urbanas Sob Cenários de Adaptação. SIMPÓSIO BRASILEIRO DE RECURSOS HÍDRICOS, 19. ABRH: Maceió, 2011. Anais... p. 1-15. Disponível em <http://www.abrh.org.br/SGCv3/ UserFiles/Sumarios/3c6e9ff325a3f3ef1d7dd6b41481084b_9e23fab32f1 c6f2fcd6b50dbecef5b6c.pdf>. Acesso em 14 mai. 2016.

HOEKSTRA, et al. Manual de Avaliação da Pegada Hídrica: Estabelecendo o Padrão Global. Tradução Solução Supernova. Revisão da Tradução de Maria Cláudia Paroni. Revisão Técnica de Henrique Marinho Leite Chaves. Revisão Final de Denise Taffarello, Albano Araújo. Water Footprint Network, 2011. 216 p. Disponível em: http:// www.ayhoekstra.nl/pubs/Hoekstra-et-al-2013ManualDeAvaliacaoDaPegadaHidrica.pdf LEÃO, R. de S. Pegada Hídrica: visões e reflexões sobre sua aplicação. Revista Ambiente \& Sociedade. São Paulo, v. XVI, n.4, p. 159-162, out.-dez. 2013.

MERRETT, $S$, et al. Virtual Water - the water, food, and Trade Nexus Useful Concept or Misleading Metaphor? IWRA, Water International, v. 28, n 1, p. 4-11, March 2003. Disponível em: <https://www.soas.ac.uk/water/publications/papers/file38394.pdf>. Acesso em 05 mai. 2016.

MMA - MINISTÉRIO DO MEIO AMBIENTE. Plano Nacional de Recursos Hídricos. Panorama e estado dos recursos hídricos do Brasil. Brasília: MMA, v. 1, 2006. 288 p. MMA - MINISTÉRIO DO MEIO AMBIENTE. Plano Nacional de Recursos Hídricos: Prioridades 2012-2015. Brasília: MMA, 2011. 124 p.

ONU. Nações Unidas. Departamento de Assuntos Econômicos e Sociais, Divisão de População (2015). World Population Prospects: The 2015 Revision, principais resultados e tabelas de antecedência. ESA / P / WP.241. p. 1-66. Disponível em: <http://esa.un.org/unpd/wpp/Publications/Files/Key_Findings_WPP_2015.pdf>. Acesso em 13 jun. 2016. 
ONU BR. Nações Unidas no Brasil. Até 2030 planeta pode enfrentar déficit de água de até $\mathbf{4 0} \%$, alerta Relatório da ONU. Disponível em <http:// nacoesunidas.org/ate-2030-planeta-pode-enfrentar-deficit-de-agua-de-ate-40-alertarelatorio-da-onu/>. Acesso em: 15 de out. 2015.

REBOUÇAS, Aldo da C. Água Doce no Mundo e no Brasil. In: REBOUÇAS, et al. (org). Águas Doces no Brasil: capital ecológico, uso e conservação. São Paulo: Escrituras Editora, 2002. Capítulo 1. p. 1-36.

Recebido em agosto de 2016 Revisado em outubro de 2016 Aceito em janeiro de 2017 